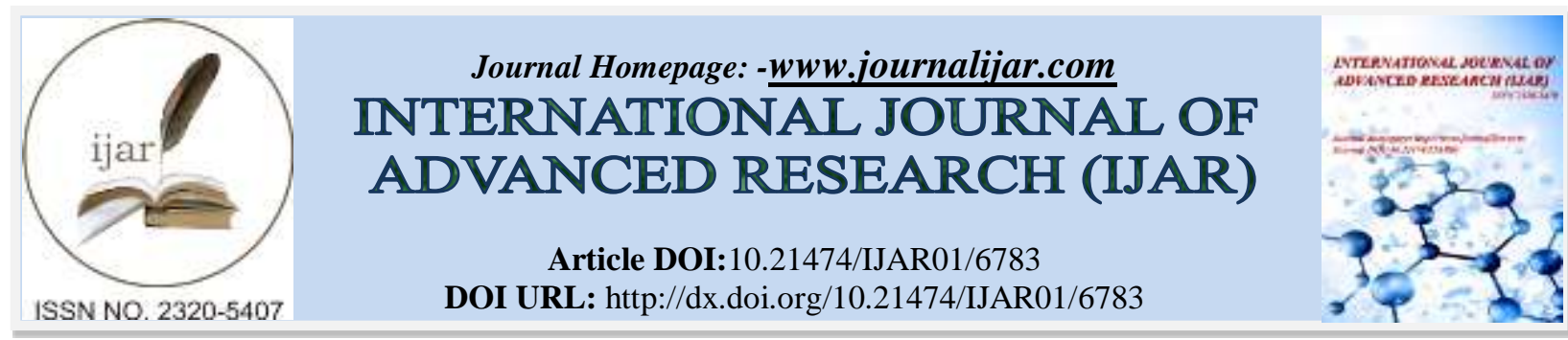

RESEARCH ARTICLE

\title{
EFFECTIVENESS OF OBJECTIVE STRUCTURED CLINICAL EXAMINATION(OSCE) AS A METHOD OF ASSESSMENT UPON SELECTED CLINICAL COMPONENTS IN CHILD HEALTH NURSING AND TO IDENTIFY THE PERCEPTION OF STUDENTS REGARDING OSCE IN SELECTED NURSING COLLEGES, PONDICHERRY
}

1. PhD Scholar, MAHER Chennai.

Prof. Malliga Kannan ${ }^{1}$ and Dr. Prof. Ani ${ }^{2}$.

2. Grace Kalaimathi, Registrar TNNMC, Guide-MAHER Chennai.

\section{Manuscript Info}

Manuscript History

Received: 19 January 2018

Final Accepted: 21 February 2018

Published: March 2018

Keywords:-

OSCE,Perception.

\section{Abstract}

Pilot study was conducted to assess the effectiveness of objective structured clinical examination as a method of assessment upon selected clinical components in child health nursing and to identify the perception of students regarding OSCE in selected nursing colleges, Pondicherry with 40 samples who were selected randomly. Consent obtained from each sample before the data collection. The OSCE stations were established. The pretest and post test conducted with the same tool. The tool reliability assessed by split half method using spearman brown's formula. The ' $r$ ' value obtained for the OSCE stations were 0.9 . The reliability of the students' perception checklist was assessed by inter-rater reliability using Pearson correlation coefficient. The ' $r$ ' value obtained was 0.8 .

Copy Right, IJAR, 2018,. All rights reserved.

\section{Introduction:-}

Assessment of clinical competence is an integral requirement of health professional education. OSCE was introduced in 1975 as a standardized tool for objectively assessing clinical competencies. A Benchmark for clinical skills [Bartfay, et al 2004] .The traditional tool for assessment of nursing students has mainly consisted of written exams, bedside viva and clinical case presentations. These have focused on the 'knows' and 'knows how' aspects. ie. The focus has been on the base of the Miller's pyramid of competence. These methods have drawn a lot of criticism due to its lack of validity and reliability.

\section{Statement Of The Problem:-}

Assess the effectiveness of objective structured clinical examination as a method of assessment upon selected clinical components in child health nursing and to identify the perception of students regarding OSCE in selected nursing colleges, Pondicherry

\section{Objectives:-}

To test the reliability - feasibility of the tool and objective structured clinical examination on selected clinical components in child health nursing and to identify the perception of students regarding OSCE in selected nursing colleges, Pondicherry. 
Methodology:-

Research Approach:-

Quantitative research approach was used to evaluate the effectiveness of OSCE.

Research Design:-

True experimental study with pre-test and post-test design.

\begin{tabular}{|l|l|l|l|}
\hline Group & Design & Post test \\
\hline Experimental group & Pretest & P & Post test \\
\hline Control group & Pretest & - & \\
\hline
\end{tabular}

\section{Research Setting:-}

The setting for the study is Child health nursing laboratory, Indirani College of nursing. This setting contains the OSCE stations with the needed child health nursing procedures in a clinically simulated environment. The existing OSCE lab was modified as per the investigator's requirement. The numbers of OSCE stations were arranged in a sequential manner.

\section{Population:-}

The population for the present study comprised of the nursing students from various nursing colleges in puducherry. It includes the B.sc (N) and DGNM students who have child health nursing as one of their study subject in the curriculum at the time of data collection. Child health Nursing is included in the III year B.sc (N) and III year DGNM curriculum. Totally there were around 600 nursing students from the III year is available from seven Nursing colleges in puducherry.

\section{Sample:-}

Samples includes the IV year B.SC (N), I year P.B.B.sc (N) and III year DGNM students who were fulfilling the inclusion criteria

\section{Sample size:-}

The sample size is 44. In that total samples, 22 samples selected for experimental group and 22 samples for control group.

\section{Sampling techniques:-}

Samples were selected by Simple random sampling technique by computer generated random numbers.

\section{Variables:-}

\section{Dependent Variable:-}

It is the clinical competence of nursing students in selected child health nursing procedures and their perception about OSCE method of examination.

\section{Independent Variable:-}

It is the effectiveness of OSCE on selected clinical components in child health nursing.

\section{Extraneous variable:-}

It includes the Age, sex, Religion, year of study, course of study, study institution, Exposure to information on OSCE and source of information.

\section{Sampling criteria:-}

\section{Inclusion Criteria:-}

1. Nursing students who have child health nursing as their study subject.

2. Students who are doing IV year B.Sc. (N), I year P.B.B.sc(N) and III year DGNM.

3. Nursing student studying in nursing colleges at Pondicherry.

\section{Exclusion Criteria:-}

1. Students who are not available at the time of data collection. 
2. Students who are not willing to participate in the study.

3. Post graduate nursing students

4. Students doing Auxiliary Nurse Midwives course.

Development and description of the tool:-

Part I:- Demographic Variables

It includes the variables like Age, Gender, Religion, Year of study, Course studying, Study Institution, Exposure to information about OSCE, Source of information

Part II:- checklist was used to assess the skill of students in these OSCE stations.

\begin{tabular}{|l|l|l|}
\hline Station & Procedure & Domain \\
\hline Station -1 & TEMPRATURE RECORDING & Skill \\
\hline Station -2 & MEASURING BLOOD PRESSURE & Skill \\
\hline Station -3 & KANGAROO MOTHER CARE & Skill \\
\hline Station -4 & RESTING STATION & ---- \\
\hline Station -5 & CARE OF BABY IN RADIANT WARMER & Skill \\
\hline Station -6 & RESTRAINTS APPLICATION & Skill \\
\hline Station -7 & CARE OF BABY IN PHOTOTHERAPY & Skill \\
\hline Station -8 & PHYSICAL EXAMINATION & Skill \\
\hline Station -9 & RESTING STATION & ---- \\
\hline Station -10 & NEW BORN RESUSCITATION & knowledge \\
\hline Station -11 & ANTHROPOMETRIC MEASUREMENTS & Skill \\
\hline Station -12 & HISTORY COLLECTION & knowledge \\
\hline
\end{tabular}

Part III:- It consists of perception checklist to assess the perception of students regarding OSCE.

\section{Results And Discussion:-}

The reliability of the data collection tools was assessed indicates that the ' $r$ ' value obtained for the OSCE stations was 0.9 . The reliability of the students perception checklist was assessed by inter-rator reliability using Pearson correlation coefficient. The ' $r$ ' value obtained was 0.8 . Data were analyzed using descriptive statistics mean and standard deviation, inferential statistics unpaired t test to test the effectiveness of OSCE method.

Table 1:-

Showed that distribution of samples in experimental and control group based on demographic variables. Homogeneity was maintained between the experimental and control group.

Table 2:-

Showed that distribution of samples based on the skill score between the pretest and post test among experimental group indicates that the OSCE was effective in improving the nursing care skills.

Table 3:-

Showed that distribution of samples based on the skill score between the pretest and post test among control group indicates that the OSCE was effective in improving the nursing care skills.

Table 4:-

Showed that OSCE checklist and perception checklist tool was most reliable.

Table 5:-

Showed that there is a significant increase in the skill performance between the pretest and post test among experimental group indicates that the OSCE was effective in improving the nursing care skills.

Table 6:-

Showed that there is a significant satisfactory perception level between the pretest and post test among the experimental group. 
Table No.1:- Frequency distribution based on Demographic Variables

$\mathrm{n}=40$

Demographic variables

\begin{tabular}{|c|c|c|c|c|c|}
\hline & & & & & \\
\hline \multirow[t]{3}{*}{ Age } & $17-18$ years & 0 & 0 & 0 & 0 \\
\hline & $18-19$ years & 10 & 50 & 11 & 55 \\
\hline & $>19$ years & 10 & 50 & 09 & 45 \\
\hline \multirow[t]{2}{*}{ Sex } & Male & 04 & 20 & 06 & 30 \\
\hline & Female & 16 & 80 & 14 & 70 \\
\hline \multirow[t]{3}{*}{ Course of study } & DGNM & 04 & 20 & 06 & 30 \\
\hline & B.SC (N) & 11 & 55 & 09 & 45 \\
\hline & P.B.B.Sc(N) & 05 & 25 & 05 & 25 \\
\hline \multirow[t]{3}{*}{ Year of study } & III year DGNM & 04 & 20 & 06 & 30 \\
\hline & III year B.SC $(\mathrm{N})$ & 11 & 55 & 09 & 45 \\
\hline & P.B.B.Sc. $(\mathrm{N})$ & 05 & 25 & 05 & 25 \\
\hline \multirow[t]{4}{*}{ Institution of study } & AGP college of Nursing & 20 & 100 & 20 & 100 \\
\hline & SMVNC & 0 & 0 & 0 & 0 \\
\hline & VINAYAGA MISSION & 0 & 0 & 0 & 0 \\
\hline & RAAK & 0 & 0 & 0 & 0 \\
\hline \multirow{4}{*}{$\begin{array}{l}\text { Exposure to } \\
\text { information regarding } \\
\text { OSCE }\end{array}$} & Workshop/conference & 0 & 0 & 0 & 0 \\
\hline & Book/Journals & 0 & 0 & 0 & 0 \\
\hline & Previous examination & 0 & 0 & 0 & 0 \\
\hline & None of the above & 20 & 100 & 20 & 100 \\
\hline \multirow[t]{2}{*}{ Place of living } & Urban & 12 & 60 & 10 & 50 \\
\hline & Rural & 08 & 40 & 10 & 50 \\
\hline \multirow[t]{3}{*}{ Religion } & Hindu & 16 & 80 & 15 & 75 \\
\hline & Muslim & 02 & 10 & 03 & 15 \\
\hline & Christian & 02 & 10 & 02 & 10 \\
\hline
\end{tabular}

Table No 2:- Frequency and Percentage distribution of pretest and posttest level of OSCE score in the Experimental group:

\begin{tabular}{|c|c|c|c|c|}
\hline \multirow{2}{*}{ OSCE Score } & \multicolumn{2}{|c|}{ Pre test } & \multicolumn{2}{c|}{ Post test } \\
\cline { 2 - 5 } & $\mathbf{n}$ & $\mathbf{\%}$ & $\mathbf{n}$ & 0 \\
\hline$<50$ & 0 & 0 & 0 & 0 \\
\hline $51-60$ & 09 & 45 & 0 & 55 \\
\hline $61-75$ & 09 & 45 & 11 & 09 \\
\hline
\end{tabular}

Table No: 3: Frequency and Percentage distribution of pre test and post test level of OSCE score in the control

\begin{tabular}{|l|c|c|c|c|} 
group. & \multicolumn{2}{c|}{ Post test } \\
\hline \multirow{2}{*}{ OSCE Score } & \multicolumn{2}{|c|}{ Pre test } & N & \% \\
\cline { 2 - 5 } & n & \% & 0 & 0 \\
\hline$<50$ & 0 & 0 & 10 & 50 \\
\hline $51-60$ & 08 & 40 & 08 & 40 \\
\hline $61-75$ & 07 & 25 & 02 & 10 \\
\hline$>75$ & 05 & & & 0 \\
\hline
\end{tabular}

Table No 4:- Comparison of post-test level of Skill difference between the experimental and control group.

\begin{tabular}{|c|c|c|c|}
\hline Post test & Mean & SD & Unpaired t test \\
\hline Experimental Group & 74.8 & 5.9 & $\mathbf{t}=\mathbf{5 . 5 4 7 3}$ \\
Control Group & 62.4 & 8.07 & $\mathbf{d f}=\mathbf{3 8}$ \\
\hline
\end{tabular}

This table showed that OSCE was effective in increasing the skill of Nursing students. 
Table No 5:- Reliability of tools for OSCE stations and Perception checklist

\begin{tabular}{|c|c|c|}
\hline Checklist & Mean & r value \\
\hline OSCE tool & 64.1 & 0.9 \\
\hline Perception tool & 80.25 & 0.8 \\
\hline
\end{tabular}

Table No 6:- Comparison of post-test level of Perception between the experimental and control group.

\begin{tabular}{|l|l|l|c|}
\hline Post test & Mean & SD & Unpaired t test \\
\hline Experimental Group & 80.05 & 3.82 & $\mathbf{t}=\mathbf{5 . 8 0 9 7}$ \\
\hline Control Group & 70.7 & 6.10 & $\mathbf{d f}=\mathbf{3 8}$ \\
\hline
\end{tabular}

This table showed that the Perception was comparatively high among the experimental group.

\section{Discussion:-}

The main focus of this study was to test the reliability and feasibility of the data collection tools and intervention and its acceptability and effectiveness in improving the skill and perception about OSCE. The results indicated that tools used were highly reliable.

The pilot study also showed that the sampling technique, set inclusion and exclusion criteria were appropriate for sample selection. The method of administering the OSCE techniques, and the proposed analytical measures were suitable for the study. The comparison between the groups showed that there was a statistical significance. The overall plan was effective, feasible and practicable to be applied in the main study.

\section{Conclusion:-}

The pilot study on the effectiveness of OSCE as an evaluative method revealed that the data collection tools were reliable, feasible and appropriate to use for the samples in the main study and the OSCE method is effective in improving the skill performance of nursing students regarding the selected child health nursing procedures.

\section{References:-}

1. Aronowitz T,Mardin J, Journal of Prof Nurs. 2017 Mar - Apr;33(2):119-125. doi: 10.1016/j.profnurs.2016.06.003

2. Solà M(1), Pulpón AM(2), Morin V(3), Sancho R(4), Clèries X(5), Fabrellas N(6).,Nurse Educ Today. 2017 Feb;49:163-167. doi: 10.1016/j.nedt.2016.11.028. Epub 2016,Dec 7.

3. Jelly $\mathrm{P}(1)$, Sharma $\mathrm{R}(1)$. Iran Journal of Nurse Midwifery Res. 2017 Jan-Feb;22(1):78-80. doi:10.4103/ijnmr.IJNMR_107_16.

4. McInulty L, Emergency Nurse. 2017 Apr 13;25(1):16. doi: 10.7748/en.25.1.16.s20.

5. Zhu X(1), Yang L(1), Br J Nurs. 2016 Jun 23;25(12):681-7. doi: 10.12968/bjon.2016.25.12.681. 